\title{
Best proximity point theorems for generalized proximal contractions
}

\author{
S Sadiq Basha ${ }^{1}$ and N Shahzad ${ }^{2 *}$
}

* Correspondence:

naseer_shahzad@hotmail.com ${ }^{2}$ Department of Mathematics, King Abdul Aziz University, P. O. Box 80203, Jeddah 21589, Saudi Arabia Full list of author information is available at the end of the article

\begin{abstract}
Best proximity point theorems unravel the techniques for determining an optimal approximate solution, designated as a best proximity point, to the equation $T x=x$ which is likely to have no solution when $T$ is a non-self mapping. This article presents best proximity point theorems for new classes of non-self mappings, known as generalized proximal contractions, in the setting of metric spaces. Further, the famous Banach's contraction principle and some of its generalizations and variants are realizable as special cases of the aforesaid best proximity point theorems.

Mathematics Subject Classification: 41A65; 46B20; 47H10.
\end{abstract}

Keywords: optimal approximate solution, fixed point, best proximity point, contraction, generalized proximal contraction

\section{Introduction}

Fixed point theory focusses on the strategies for solving non-linear equations of the kind $T x=x$ in which $T$ is a self mapping defined on a subset of a metric space, a normed linear space, a topological vector space or some pertinent framework. But, when $T$ is not a self-mapping, it is plausible that $T x=x$ has no solution. Subsequently, one targets to determine an element $x$ that is in some sense close proximity to $T x$. In fact, best approximation theorems and best proximity point theorems are suitable to be explored in this direction. A well known best approximation theorem, due to Fan [1], ascertains that if $K$ is a non-empty compact convex subset of a Hausdorff locally convex topological vector space $E$ and $T: K \rightarrow E$ is a continuous non-self mapping, then there exists an element $x$ in such a way that $d(x, T x)=d(T x, K)$. Several authors, including Prolla [2], Reich [3] and Sehgal and Singh [4,5], have accomplished extensions of this theorem in various directions. Moreover, a result that unifies all such best approximation theorems has been obtained by Vetrivel et al. [6].

Despite the fact that the best approximation theorems are befitting for furnishing an approximate solution to the equation $T x=x$, such results may not afford an approximate solution that is optimal. On the other hand, best proximity point theorems offer an approximate solution that is optimal. Indeed, a best proximity point theorem details sufficient conditions for the existence of an element $x$ such that the error $d(x, T x)$ is minimum. A best proximity point theorem is fundamentally concerned with the global minimization of the real valued function $x \rightarrow d(x, T x)$ that is an indicator of the error involved for an approximate solution of the equation $T x=x$. Because of the fact that,

(c) 2012 Basha and Shahzad; licensee Springer. This is an Open Access article distributed under the terms of the Creative Commons Attribution License (http://creativecommons.org/licenses/by/2.0), which permits unrestricted use, distribution, and reproduction in any medium, provided the original work is properly cited. 
for a non-self mapping $T: A \rightarrow B, d(x, T x)$ is at least $d(A, B)$ for all $x$ in $A$, a best proximity point theorem ensures global minimum of the error $d(x, T x)$ by confining an approximate solution $x$ of the equation $T x=x$ to comply with the condition that $d$ $(x, T x)=d(A, B)$. Such an optimal approximate solution of the equation $T x=x$ is said to be a best proximity point of the non-self mapping $T: A \rightarrow B$. Moreover, it can be seen that best proximity point theorems emerge as a natural extension of fixed point theorems, since a best proximity point boils down to a fixed point when the underlying mapping turns out to be a self-mapping.

A best proximity point theorem for contraction has been explicated in [7]. The existence of a best proximity point for proximal pointwise contractions has been probed by Anuradha and Veeramani [8]. Furthermore, many best proximity point theorems for several variants of contractions have been analyzed in [9-15]. Anthony Eldred et al. [16] have established a best proximity point theorem for relatively non-expansive mappings, a different treatment to which has been furnished in [17]. A best proximity point theorem for contractive mappings has been presented in [18]. Some interesting common best proximity point theorems have been explored in $[19,20]$. Also, best proximity point theorems for various kinds of multi-valued mappings have been accomplished in [21-31].

The primary objective of this article is to provide best proximity point theorems for generalized proximal contractions of the first and the second kinds in the setting of complete metric spaces, thereby ascertaining an optimal approximate solution to the equation $T x=x$, where $T: A \rightarrow B$ is a generalized proximal contraction of the first kind or a generalized proximal contraction of the second kind. It is remarked that the preceding best proximity point theorems include the well-known Banach's contraction principle and some of its generalizations and variants as special cases.

\section{Preliminaries}

Given non-void subsets $A$ and $B$ of a metric space, this section recalls the following notations and notions that will be used in the sequel.

$$
\begin{aligned}
& d(A, B):=\inf \{d(x, y): x \in A \text { and } y \in B\} \\
& A_{0}:=\{x \in A: d(x, y)=d(A, B) \text { for some } y \in B\} \\
& B_{0}:=\{y \in B: d(x, y)=d(A, B) \text { for some } x \in A\}
\end{aligned}
$$

If $A$ and $B$ are closed subsets of a normed linear space such that $d(A, B)>0$, then $A_{0}$ and $B_{0}$ are contained in the boundaries of $A$ and $B$ respectively [26].

Definition 2.1. A mapping $T: A \rightarrow B$ is said to be a generalized proximal contraction of the first kind if there exist non-negative numbers $\alpha, \beta, \gamma, \delta$ with $\alpha+\beta+\gamma+2 \delta$ $<1$ such that the conditions

$$
d\left(u_{1}, T x_{1}\right)=d(A, B) \text { and } d\left(u_{2}, T x_{2}\right)=d(A, B)
$$

imply the inequality that

$$
d\left(u_{1}, u_{2}\right) \leq \alpha d\left(x_{1}, x_{2}\right)+\beta d\left(x_{1}, u_{1}\right)+\gamma d\left(x_{2}, u_{2}\right)+\delta\left[d\left(x_{1}, u_{2}\right)+d\left(x_{2}, u_{1}\right)\right]
$$

for all $u_{1}, u_{2}, x_{1}, x_{2}$ in $A$.

If $T$ is a self-mapping on $A$, then the requirement in the preceding definition reduces to the condition that 


$$
d\left(T x_{1}, T x_{2}\right) \leq \alpha d\left(x_{1}, x_{2}\right)+\beta d\left(x_{1}, T x_{1}\right)+\gamma d\left(x_{2}, T x_{2}\right)+\delta\left[d\left(x_{1}, T x_{2}\right)+d\left(x_{2}, T x_{1}\right)\right]
$$

Definition 2.2. A mapping $T: A \rightarrow B$ is said to be a generalized proximal contraction of the second kind if there exist non-negative numbers $\alpha, \beta, \gamma, \delta$ with $\alpha+\beta+\gamma+$ $2 \delta<1$ such that the conditions

$$
d\left(u_{1}, T x_{1}\right)=d(A, B) \text { and } d\left(u_{2}, T x_{2}\right)=d(A, B)
$$

imply the inequality

$$
\begin{array}{r}
d\left(T u_{1}, T u_{2}\right) \leq \alpha d\left(T x_{1}, T x_{2}\right)+\beta d\left(T x_{1}, T u_{1}\right)+\gamma d\left(T x_{2}, T u_{2}\right) \\
+\delta\left[d\left(T x_{1}, T u_{2}\right)+d\left(T x_{2}, T u_{1}\right)\right]
\end{array}
$$

for all $u_{1}, u_{2}, x_{1}, x_{2}$ in $A$.

It is easy to see that a mapping that is a generalized proximal contraction of the second kind is not necessarily a generalized proximal contraction of the first kind. For Let $A:=\{(-1, x): x \in R\}$
instance, consider the space $R^{2}$ with Euclidean metric.
Let $B:=\{(1, x): x \in R\}$

Let $T: A \rightarrow B$ be defined as

$$
T((-1, x))=\left\{\begin{array}{l}
(1,1) \text { if } x \text { is rational } \\
(1,-1) \text { otherwise }
\end{array}\right.
$$

Then, $T$ is a generalized proximal contraction of the second kind but not a generalized proximal contraction of the first kind. Further, it can be observed that the generalized proximal contractions are not necessarily continuous.

Definition 2.3. The set $B$ is said to be approximatively compact with respect to $A$ if every sequence $\left\{y_{n}\right\}$ of $B$ satisfying the condition that $d\left(x, y_{n}\right) \rightarrow d(x, B)$ for some $x$ in $A$ has a convergent subsequence.

It is obvious that any compact set is approximatively compact, and that any set is approximatively compact with respect to itself. Further, if $A$ is compact and $B$ is approximatively compact with respect to $A$, then it is ensured that $A_{0}$ and $B_{0}$ are nonempty. In the setting of reflexive Banach spaces, if $A$ is a non-void, closed, bounded and convex subset and $B$ is a non-void, closed and convex subset, then it is guaranteed that $A_{0}$ and $B_{0}$ are non-void [24].

\section{Generalized proximal contractions}

The following main result is a best proximity point theorem for non-self generalized proximal contractions of the first kind, which are not necessarily continuous.

Theorem 3.1. Let $A$ and $B$ be non-void, closed subsets of a complete metric space such that $B$ is approximatively compact with respect to $A$. Also, suppose that $A_{0}$ and $B_{0}$ are non-void. Let $T: A \rightarrow B$ satisfy the following conditions:

(a) $T$ is a generalized proximal contraction of the first kind.

(b) $T\left(A_{0}\right)$ is contained in $B_{0}$.

Then, there exists a unique element $x$ in $A$ such that

$$
d(x, T x)=d(A, B)
$$


Further, for any fixed element $x_{0} \in A_{0}$, the sequence $\left\{x_{n}\right\}$, defined by

$$
d\left(x_{n+1}, T x_{n}\right)=d(A, B),
$$

converges to the best proximity point $x$.

Proof. Let us select an element $x_{0}$ in $A_{0}$. On account of the fact $T\left(A_{0}\right)$ is contained in $B_{0}$, it is guaranteed that there is an element $x_{1}$ in $A_{0}$ satisfying the condition that

$$
d\left(x_{1}, T x_{0}\right)=d(A, B) .
$$

Further, since $T x_{1}$ is a member of $T\left(A_{0}\right)$ which is contained in $B_{0}$, it follows that there is an element $x_{2}$ in $A_{0}$ such that

$$
d\left(x_{2}, T x_{1}\right)=d(A, B) .
$$

This process can be continued further. Having chosen $x_{n}$ in $A_{0}$, it is ascertained that there exists an element $x_{n+1}$ in $A_{0}$ satisfying the condition that

$$
d\left(x_{n+1}, T x_{n}\right)=d(A, B),
$$

for every non-negative integer $n$ because of the hypothesis that $T\left(A_{0}\right)$ is contained in $B_{0}$. In view of the fact $T$ is a generalized proximal contraction of the first kind, we have that

$$
\begin{aligned}
d\left(x_{n}, x_{n+1}\right) \leq & \alpha d\left(x_{n-1}, x_{n}\right)+\beta d\left(x_{n-1}, x_{n}\right)+\gamma d\left(x_{n}, x_{n+1}\right)+\delta d\left(x_{n-1}, x_{x+1}\right) \\
\leq & \alpha d\left(x_{n-1}, x_{n}\right)+\beta d\left(x_{n-1}, x_{n}\right)+\gamma d\left(x_{n}, x_{n+1}\right) \\
& +\delta\left[d\left(x_{n-1}, x_{n}\right)+d\left(x_{n}, x_{n+1}\right)\right]
\end{aligned}
$$

As a consequence, we get

$$
d\left(x_{n}, x_{n+1}\right) \leq k d\left(x_{n-1}, x_{n}\right)
$$

where the constant $k=\frac{(\alpha+\beta+\delta)}{(1-\gamma-\delta)}$ is strictly less than 1 . Therefore, $\left\{x_{n}\right\}$ is a Cauchy sequence. Because the space is complete, the sequence $\left\{x_{n}\right\}$ converges to some element $x$ in $A$.

$$
\text { Furthermore, } \begin{aligned}
d(x, B) \leq & d\left(x, T x_{n}\right) \leq d\left(x, x_{n+1}\right)+d\left(x_{x+1}, T x_{n}\right) \\
& =d\left(x, x_{n+1}\right)+d(A, B) \\
& \leq d\left(x, x_{n+1}\right)+d(x, B) .
\end{aligned}
$$

Therefore, $d\left(x, T x_{n}\right) \rightarrow d(x, B)$. In light of the fact that $B$ is approximatively compact with respect to $A$, the sequence $\left\{T x_{n}\right\}$ has a subsequence $\left\{T x_{n_{k}}\right\}$ converging to some element $y$ in $B$. So, it results that

$$
d(x, y)=\lim _{n \rightarrow \infty} d\left(x_{n_{k}+1}, T x_{n_{k}}\right)=d(A, B),
$$

and hence $x$ must be a member of $A_{0}$. Because of the fact that $T\left(A_{0}\right)$ is contained in $B_{0}$,

$$
d(u, T x)=d(A, B)
$$

for some element $u$ in $A$. Since $T$ is a generalized proximal contraction of the first kind, it follows that 


$$
d\left(u, x_{n+1}\right) \leq \alpha d\left(x, x_{n}\right)+\beta d(u, x)+\gamma d\left(x_{n}, x_{n+1}\right)+\delta\left[d\left(x, x_{n+1}\right)+d\left(x_{n}, u\right)\right] .
$$

Letting $n \rightarrow \infty$,

$$
d(u, x) \leq(\beta+\delta) d(u, x),
$$

which in turn necessitates that $x$ and $u$ must be identical. Thus, it follows that

$$
d(x, T x)=d(u, T x)=d(A, B) .
$$

Suppose that there is another best proximity point $x^{*}$ of the mapping $T$ so that

$$
d\left(x^{*}, T x^{*}\right)=d(A, B) .
$$

As $T$ is a generalized proximal contraction of the first kind,

$$
d\left(x, x^{*}\right) \leq(\alpha+2 \delta) d\left(x, x^{*}\right) .
$$

Consequently, $x$ and $x *$ must be identical. Hence, $T$ has a unique best proximity point. This completes the proof of the theorem.

The preceding best proximity point theorem subsumes the following result which serves as a non-self mapping analogue of the famous Banach's contraction principle.

Corollary 3.2. Let $A$ and $B$ be non-empty, closed subsets of a complete metric space such that $B$ is approximatively compact with respect to $A$. Further, assume that $A_{0}$ and $B_{0}$ are non-void. Let $T: A \rightarrow B$ satisfy the following conditions:

(a) There exists a non-negative real number $\alpha<1$ such that, for all $u_{1}, u_{2}, x_{1}, x_{2}$ in the domain $A$,

$$
\left.\begin{array}{l}
d\left(u_{1}, T x_{1}\right)=d(A, B) \\
d\left(u_{2}, T x_{2}\right)=d(A, B)
\end{array}\right\} \Rightarrow d\left(u_{1}, u_{2}\right) \leq \alpha d\left(x_{1}, x_{2}\right)
$$

(b) $T\left(A_{0}\right) \subseteq B_{0}$.

Then, there exists a unique element $x \in A$ such that

$$
d(x, T x)=d(A, B)
$$

Further, for any fixed element $x_{0} \in A_{0}$, the sequence $\left\{x_{n}\right\}$, defined by

$$
d\left(x_{n+1}, T x_{n}\right)=d(A, B),
$$

converges to the best proximity point $x$.

The best proximity point Theorem 3.1 includes the following fixed point theorem as a special case.

Corollary 3.3. Let $T$ be a self-mapping on a complete metric space. Further, let us assume that there exist non-negative real numbers $\alpha, \beta, \gamma, \delta$ with $\alpha+\beta+\gamma+2 \delta<1$ such that

$$
d\left(T x_{1}, T x_{2}\right) \leq \alpha d\left(x_{1}, x_{2}\right)+\beta d\left(x_{1}, T x_{1}\right)+\gamma d\left(x_{2}, T x_{2}\right)+\delta\left[d\left(x_{1}, T x_{2}\right)+d\left(x_{2}, T x_{1}\right)\right]
$$


for all $x_{1}, x_{2}$ in the domain of the mapping $T$. Then the mapping $T$ has a unique fixed point.

The following main result is a best proximity point theorem for non-self generalized proximal contractions of the second kind.

Theorem 3.4. Let $A$ and $B$ be non-void, closed subsets of a complete metric space such that $A$ is approximatively compact with respect to $B$. Also, suppose that $A_{0}$ and $B_{0}$ are non-void. Let $T: A \rightarrow B$ satisfy the following conditions:

(a) $T$ is a continuous generalized proximal contraction of the second kind.

(b) $T\left(A_{0}\right)$ is contained in $B_{0}$.

Then, there exists an element $x$ in $A$ such that

$$
d(x, T x)=d(A, B),
$$

and the sequence $\left\{x_{n}\right\}$ converges to the best proximity point $x$, where $x_{0}$ is any fixed element in $A_{0}$ and $d\left(x_{n+1}, T x_{n}\right)=d(A, B)$ for $n \geq 0$.

Further, if $x^{*}$ is another best proximity point of $T$, then $T x=T x^{*}$, and hence $T$ is a constant on the set of all best proximity points of $T$.

Proof. Proceeding as in Theorem 3.1, it is possible to find a sequence $\left\{x_{n}\right\}$ in $A_{0}$ such that

$$
d\left(x_{n+1}, T x_{n}\right)=d(A, B)
$$

for all non-negative integral values of $n$. In view of the fact that $T$ is a generalized proximal contraction of the second kind,

$$
\begin{gathered}
d\left(T x_{n}, T x_{n+1}\right) \leq \alpha d\left(T x_{n-1}, T x_{n}\right)+\beta d\left(T x_{n-1}, T x_{n}\right)+\gamma d\left(T x_{n}, T x_{n+1}\right) \\
+\delta d\left(T x_{n-1}, T x_{n+1}\right) \\
\leq \alpha d\left(T x_{n-1}, T x_{n}\right)+\beta d\left(T x_{n-1}, T x_{n}\right)+\gamma d\left(T x_{n}, T x_{n+1}\right) \\
+\delta\left[d\left(T x_{n-1}, T x_{n}\right)+d\left(T x_{n}, T x_{n+1}\right)\right] .
\end{gathered}
$$

As a result,

$$
d\left(T x_{n}, T x_{n+1}\right) \leq k d\left(T x_{n-1}, T x_{n}\right)
$$

where the constant $k=\frac{(\alpha+\beta+\delta)}{(1-\gamma-\delta)}$ is strictly less than 1 . Eventually, $\left\{T x_{n}\right\}$ is a Cauchy sequence. Since the space is complete, the sequence $\left\{T x_{n}\right\}$ converges to some element $y$ in $B$.

$$
\text { Moreover, } \begin{aligned}
d(y, A) \leq d\left(\gamma, x_{n+1}\right) & \leq d\left(\gamma, T x_{n}\right)+d\left(T x_{n}, x_{n+1}\right) \\
& =d\left(y, T x_{n}\right)+d(A, B) \\
& \leq d\left(y, T x_{n}\right)+d(y, A) .
\end{aligned}
$$

Thus, $d\left(y, x_{n}\right) \rightarrow d(x, B)$. In view of the fact that $A$ is approximatively compact with respect to $B$, the sequence $\left\{x_{n}\right\}$ has a subsequence $\left\{x_{n_{k}}\right\}$ converging to some element $x$ in $A$. Since $T$ is a continuous mapping,

$$
d(x, T x)=\lim _{n \rightarrow \infty} d\left(x_{n+1}, T x_{n}\right)=d(A, B) .
$$


Let us assume that there is another best proximity point $x^{*}$ in $A$ so that

$$
d\left(x^{*}, T x^{*}\right)=d(A, B) .
$$

Because $T$ is a generalized proximal contraction of the second kind,

$$
d\left(T x, T x^{*}\right) \leq(\alpha+2 \delta) d\left(T x, T x^{*}\right),
$$

which mandates that $T x=T x^{*}$. This completes the proof of the theorem.

The preceding best proximity point theorem contains the following result which serves as a non-self mapping analogue of the famous Banach's contraction principle.

Corollary 3.5. Let $A$ and $B$ be non-empty, closed subsets of a complete metric space such that $A$ is approximatively compact with respect to $B$. Further, assume that $A_{0}$ and $B_{0}$ are non-void. Let $T: A \rightarrow B$ satisfy the following conditions:

(a)There exists a non-negative real number $\alpha<1$ such that, for all $u_{1}, u_{2}, x_{1}, x_{2}$ in the domain $A$,

$$
\left.\begin{array}{l}
d\left(u_{1}, T x_{1}\right)=d(A, B) \\
d\left(u_{2}, T x_{2}\right)=d(A, B)
\end{array}\right\} \Rightarrow d\left(T u_{1}, T u_{2}\right) \leq \alpha d\left(T x_{1}, T x_{2}\right)
$$

(b) $T$ is continuous.

(c) $T\left(A_{0}\right) \subseteq B_{0}$.

Then, there exists an element $x \in A$ such that

$$
d(x, T x)=d(A, B)
$$

If $x^{*}$ is another best proximity point of $T$, then $T x=T x^{*}$.

sFurther, for any fixed element $x_{0} \in A_{0}$, the sequence $\left\{x_{n}\right\}$, defined by

$$
d\left(x_{n+1}, T x_{n}\right)=d(A, B),
$$

converges to a best proximity point of the mapping $T$.

The following best proximity point theorem is for non-self mappings which are generalized proximal contractions of the first kind as well as generalized proximal contractions of the second kind without the assumption of approximatively compactness of the domains or the co-domains of the mappings.

Theorem 3.6. Let $A$ and $B$ be non-void, closed subsets of a complete metric space. Also, suppose that $A_{0}$ and $B_{0}$ are non-void. Let $T: A \rightarrow B$ satisfy the following conditions:

(a) $T$ is a generalized proximal contraction of the first kind as well as a generalized proximal contraction of the second kind.

(b) $T\left(A_{0}\right)$ is contained in $B_{0}$.

Then, there exists a unique element $x$ in $A$ such that

$$
d(x, T x)=d(A, B)
$$


and the sequence $\left\{x_{n}\right\}$ converges to the best proximity point $x$, where $x_{0}$ is any fixed element in $A_{0}$ and $d\left(x_{n+1}, T x_{n}\right)=d(A, B)$ for $n \geq 0$.

Proof. Proceeding as in Theorem 3.1, it is possible to find a sequence $\left\{x_{n}\right\}$ in $A_{0}$ such that

$$
d\left(x_{n+1}, T x_{n}\right)=d(A, B)
$$

for all non-negative integral values of $n$. As in Theorem 3.1, it can be shown that the sequence $\left\{x_{n}\right\}$ is a Cauchy sequence and hence converges to some element $x$ in $A$. Further, as in Theorem 3.4, it can be asserted that the sequence $\left\{T x_{n}\right\}$ is a Cauchy sequence and hence converges to some element $y$ in $B$. Therefore, it follows that

$$
d(x, y)=\lim _{n \rightarrow \infty} d\left(x_{n+1}, T x_{n}\right)=d(A, B) .
$$

Eventually, $x$ becomes an element of $A_{0}$. In light of the fact that $T\left(A_{0}\right)$ is contained in $B_{0}$,

$$
d(u, T x)=d(A, B)
$$

for some element $u$ in $A$. Since $T$ is a generalized proximal contraction of the first kind, it can be seen that

$$
d\left(u, x_{n+1}\right) \leq \alpha d\left(x, x_{n}\right)+\beta d(u, x)+\gamma d\left(x_{n}, x_{n+1}\right)+\delta\left[d\left(x, x_{n+1}\right) d\left(x_{n}, u\right)\right] .
$$

Letting $n \rightarrow \infty, d(u, x) \leq(\beta+\delta) d(u, x)$, which implies that $x$ and $u$ must be identical. Thus, it follows that

$$
d(x, T x)=d(u, T x)=d(A, B) .
$$

Also, the uniqueness of the best proximity point of the mapping $T$ follows as in Theorem 3.1. This completes the proof of the theorem.

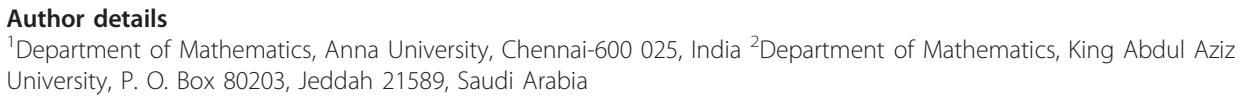

1. Fan, K: Extensions of two fixed point theorems of F. E. Browder. Math Z. 112, 234-240 (1969). doi:10.1007/BF01110225

2. Prolla, JB: Fixed point theorems for set valued mappings and existence of best approximations. Numer Funct Anal Optim. 5, 449-455 (1982)

3. Reich, S: Approximate selections, best approximations, fixed points and invariant sets. J Math Anal Appl. 62, 104-113 (1978). doi:10.1016/0022-247X(78)90222-6

4. Sehgal, VM, Singh, SP: A generalization to multifunctions of Fan's best approximation theorem. Proc Am Math Soc. 102, 534-537 (1988)

5. Sehgal, VM, Singh, SP: A theorem on best approximations. Numer Funct Anal Optim. 10, 181-184 (1989). doi:10.1080/ 01630568908816298

6. Vetrivel, V, Veeramani, P, Bhattacharyya, P: Some extensions of Fan's best approximation theorem. Numer Funct Anal Optim. 13, 397-402 (1992). doi:10.1080/01630569208816486

7. Sadiq Basha, S: Extensions of Banach's contraction principle. Numer Funct Anal Optim. 31, 569-576 (2010). doi:10.1080/ 01630563.2010 .485713 
8. Anuradha, J, Veeramani, P: Proximal pointwise contraction. Topol Appl. 156(18):2942-2948 (2009). doi:10.1016/j. topol.2009.01.017

9. Al-Thagafi, MA, Shahzad, N: Convergence and existence results for best proximity points. Nonlinear Anal. 70(10):3665-3671 (2009). doi:10.1016/j.na.2008.07.022

10. Anthony Eldred, A, Veeramani, PL: Existence and convergence of best proximity points. J Math Anal Appl. 323, 1001-1006 (2006). doi:10.1016/j.jmaa.2005.10.081

11. Di Bari, C, Suzuki, T, Vetro, C: Best proximity points for cyclic Meir-Keeler contractions. Nonlinear Anal. 69(11):3790-3794 (2008). doi:10.1016/j.na.2007.10.014

12. Karpagam, S, Agrawal, S: Best proximity point theorems for $p$-cyclic Meir-Keeler contractions. Fixed Point Theory Appl 2009, 9 (2009). Article ID 197308

13. Suzuki, T, Kikkawa, M, Vetro, C: The existence of best proximity points in metric spaces with the property UC. Nonlinear Anal. 71, 2918-2926 (2009). doi:10.1016/j.na.2009.01.173

14. Suzuki, T, Vetro, C: Three existence theorems for weak contractions of Matkowski type. Int J Math Stat. 6, 110-120 (2010). doi:10.3844/jmssp.2010.110.115

15. Vetro, C: Best proximity points: convergence and existence theorems for p-cyclic mappings. Nonlinear Anal. 73 2283-2291 (2010). doi:10.1016/i.na.2010.06.008

16. Anthony Eldred, A, Kirk, WA, Veeramani, P: Proximinal normal structure and relatively nonexpanisve mappings. Studia Math. 171(3):283-293 (2005). doi:10.4064/sm171-3-5

17. Sankar Raj, V, Veeramani, P: Best proximity pair theorems for relatively nonexpansive mappings. Appl General Topol. 10(1):21-28 (2009)

18. Sadiq Basha, S: Best proximity points: global optimal approximate solution. J Glob Optim (2010). doi:10.1007/s10898009-9521-0

19. Sadiq Basha, S, Shahzad, N, Jeyaraj, R: Common best proximity points: global optimization of multi-objective functions. Appl Math Lett. 24, 883-886 (2011). doi:10.1016/j.aml.2010.12.043

20. Shahzad, N, Sadiq Basha, S, Jeyaraj, R: Common best proximity points: global optimal solutions. J Optim Theory Appl. 148, 69-78 (2011). doi:10.1007/s10957-010-9745-7

21. Al-Thagafi, MA, Shahzad, N: Best proximity pairs and equilibrium pairs for Kakutani multimaps. Nonlinear Anal. 70(3):1209-1216 (2009). doi:10.1016/j.na.2008.02.004

22. Al-Thagafi, MA, Shahzad, N: Best proximity sets and equilibrium pairs for a finite family of multimaps. Fixed Point Theory Appl 2008 (2008). 10 (Article ID 457069)

23. Kim, WK, Kum, S, Lee, KH: On general best proximity pairs and equilibrium pairs in free abstract economies. Nonlinear Anal. 68(8):2216-2227 (2008). doi:10.1016/j.na.2007.01.057

24. Kirk, WA, Reich, S, Veeramani, P: Proximinal retracts and best proximity pair theorems. Numer Funct Anal Optim. 24 851-862 (2003). doi:10.1081/NFA-120026380

25. Sadiq Basha, S, Veeramani, P: Best approximations and best proximity pairs. Acta Sci Math (Szeged). 63, 289-300 (1997)

26. Sadiq Basha, S, Veeramani, P: Best proximity pair theorems for multifunctions with open fibres. J Approx Theory. 103, 119-129 (2000). doi:10.1006/jath.1999.3415

27. Sadiq Basha, S, Veeramani, P, Pai, DV: Best proximity pair theorems. Indian J Pure Appl Math. 32, 1237-1246 (2001)

28. Srinivasan, PS: Best proximity pair theorems. Acta Sci Math (Szeged). 67, 421-429 (2001)

29. Wlodarczyk, K, Plebaniak, R, Banach, A: Best proximity points for cyclic and noncyclic set-valued relatively quasiasymptotic contractions in uniform spaces. Nonlinear Anal. 70(9):3332-3341 (2009). doi:10.1016/j.na.2008.04.037

30. Wlodarczyk, K, Plebaniak, R, Banach, A: Erratum to: best proximity points for cyclic and noncyclic set-valued relatively quasi-asymptotic contractions in uniform spaces. Nonlinear Anal 71, 3585-3586 (2009). [Nonlinear Anal. 70, 3332-3341 (2009)]. doi:10.1016/j.na.2008.11.020

31. Wlodarczyk, K, Plebaniak, R, Obczynski, C: Convergence theorems, best approximation and best proximity for set-valued dynamic systems of relatively quasi-asymptotic contractions in cone uniform spaces. Nonlinear Anal. 72, 794-805 (2010). doi:10.1016/j.na.2009.07.024

doi:10.1186/1687-1812-2012-42

Cite this article as: Basha and Shahzad: Best proximity point theorems for generalized proximal contractions.

Fixed Point Theory and Applications 2012 2012:42.

\section{Submit your manuscript to a SpringerOpen ${ }^{\circ}$ journal and benefit from:}

- Convenient online submission

- Rigorous peer review

- Immediate publication on acceptance

- Open access: articles freely available online

- High visibility within the field

- Retaining the copyright to your article

Submit your next manuscript at $\gg$ springeropen.com 